\title{
CARACTERIZAÇÃO FÍSICA E CONDIÇÕES SANITÁRIAS DO COMÉRCIO DE QUEIJO CABACINHA EM TRÊS MUNICÍPIOS DO VALE DO JEQUITINHONHA, MG, BRASIL
}

\author{
Physical characterization and sanitary conditions of cheese \\ type cabacinha market places in three municipalities \\ of the Jequitinhonha Valley, MG, Brazil
}

\begin{abstract}
Adair da Silva Santos Filho ${ }^{1}$, Christiano Vieira Pires ${ }^{2}$, Augusto Andrade Pereira ${ }^{\text {, }}$ Weslley José Cardoso ${ }^{l}$, Maximiliano Soares Pintos ${ }^{1}$, Neide Judith Faria de Oliveira ${ }^{1 *}$
\end{abstract}

\section{RESUMO}

O queijo cabacinha, originário do Vale do Jequitinhonha, é obtido por aquecimento do coágulo, de forma semelhante à mussarela, porém a matéria prima não é pasteurizada e o produto final é armazenado sem embalagem e em temperatura ambiente. Esse derivado lácteo pode contribuir para a elevação da renda da população local, principalmente dos moradores das margens das rodovias, em função do fluxo de veículos e de possíveis compradores. Neste trabalho, objetivou-se conhecer as condições físicas e sanitárias dos locais de comércio do queijo artesanal cabacinha em três municípios do Vale do Jequitinhonha, MG, Brasil. Para tanto, inicialmente, foi realizado levantamento do número de locais de venda do derivado lácteo nos municípios de Medina, Cachoeira de Pajeú e Pedra Azul, localizados nas imediações das rodovias BR 251 e BR 116 no estado de Minas Gerais, Brasil. Posteriormente, foi elaborada planilha para averiguações da estrutura física e condições sanitárias dos locais, preenchida em nova visitação in loco. Pode-se observar que a maioria dos pontos comerciais não possuía as condições adequadas, como ausência de paredes de alvenaria, de água canalizada e de sanitários ou pias. Era comum também a presença de possíveis vetores de contaminação nas imediações dos locais de venda do produto lácteo, como cães e insetos. Verificou-se que a maior parte dos queijos era

1 Instituto de Ciências Agrárias da Universidade Federal de Minas Gerais (ICA/UFMG), Avenida Universitária, 1000, Universitário, 39404-547, Montes Claros, MG, Brasil. E-mail: neidejudith@ hotmail.com

2 Universidade Federal de São João del-Rei, Campus Sete Lagoas, Sete Lagoas, MG, Brasil.

* Autor para correspondência. 
exposta pendurada aos pares em barbantes e sem embalagem. O estudo demonstra a precariedade da estrutura física e das condições higiênico-sanitárias nos locais de comércio do queijo cabacinha. Por tratar-se de produto artesanal proveniente da agricultura familiar, que gera renda e emprego no campo, merecia mais atenção dos órgãos competentes estaduais e municipais.

Palavras-chave: queijo artesanal; comercialização; derivado lácteo; estrutura; higiene.

\begin{abstract}
Cheese type cabacinha from Vale do Jequitinhonha is obtained by curd heating in a similar process made to Mozzarella, but the raw milk is unpasteurized and the final product is stored unpackaged and at room temperature. This milk derivative may contribute to the increase the income of the local population, especially the residents of the edges of roads, due to the flow of vehicles and possible buyers. The purpose of this work was to identify the physical and sanitary conditions of cheese type cabacinha market places present in three municipalities of the Vale do Jequitinhonha, MG, Brazil. Previously the investigation was detected the number of marketplaces that sell these cheese in the Medina, Cachoeira de Pajeú and Pedra Azul, municipalities of the state of Minas Gerais, Brazil, located on the surrounding area of the highways BR 251 and BR 116. Afterward was developed a physical and sanitary checklist and it were filled in loco. It was observed that most market places were not provided of masonry walls, piped water or toilet and sink. It is also common to the presence of possible contamination vectors in surroundings, such as dogs and insects. It is verified that most of these cheese is exposed in pairs held by string and unpackaged. This study demonstrated the precariousness of the physical structures and consequently the lack of adequate sanitary conditions in the cheese type cabacinha market places. Because it is an artisanal product from family farming, which generates income and employment in the field deserve more attention of competent state and municipal authorities.
\end{abstract}

Keywords: traditional cheese; marketing; milk derivative; structure; hygiene.

\section{INTRODUÇÃO}

Investigações fundamentadas possibilitam conhecer como é realizada a comercialização de alimentos (GENTA et al., 2005), sendo aplicável ao queijo artesanal produzido no Vale do Jequitinhonha. Esse é denominado queijo cabacinha, em função da similaridade como "formato de cabaça" e possui processo de filagem parecido ao da mussarela. Porém, o leite não é submetido à pasteurização antes do processamento
(MINAS GERAIS, 2012; MINAS GERAIS, 2014).

O checklist ou lista de verificação é uma ferramenta utilizada para avaliar os elementos considerados críticos à segurança de determinado local, podendo ser aplicado em diversas situações (BRASIL, 2002). Essa avaliação permite conhecer as não conformidades para elaborar planos de ações corretivas, visando adequar as instalações, os procedimentos e os métodos produtivos, no intuito de reduzir ou minimizar riscos físicos, 
químicos e biológicos, os quais poderão comprometer os alimentos e o bem-estar do consumidor (GENTA et al., 2005).

A receita do queijo cabacinha foi introduzida em 1952 por Alberto Firmiano Mendes de Oliveira, depois de concluir o curso técnico em 1949, na Escola de Laticínios Cândido Tostes, de Juiz de Fora - MG. Muitos produtores do Vale do Jequitinhonha aprenderam o oficio com os pais, mantendo a tradição e fazendo a "receita" perdurar por anos, segundo a Empresa de Assistência Técnica e Extensão Rural do Estado de Minas Gerais (EMATER, 2008).

O queijo cabacinha é considerado a versão brasileira do "caccio cavalo", de origem italiana, feito com massa cozida em água fervente, dessorada, puxada até fazer fios, moldado, amarrado aos pares e colocado para secar, podendo ser defumado ou recheado com manteiga. $\mathrm{O}$ uso culinário deste produto lácteo é muito difundido no Sul da Itália. No Brasil é consumido principalmente como aperitivo (LATICÍNIOS CRUZILIA, 2017). Confirmando o consumo integral do queijo cabacinha, as versões defumada e temperada são identificadas no comércio (SILVEIRA, 2015).

Esse tipo de estudo é importante, pois não existem pesquisas científicas referentes ao queijo cabacinha e conforme Minas Gerais (2014), essa região foi identificada como produtora deste queijo artesanal. O laticínio pioneiro a introduzir esse tipo de queijo é mantido por parentes, assim como várias outras famílias dependem dessa renda para ajudar na subsistência, direta ou indiretamente (EMATER, 2008).

Além de pontos de venda situados nas margens das rodovias, a produção de leite fresco, doce de leite, requeijão e queijo é comercializada nas feiras livres nos municípios do Jequitinhonha, com maior frequência aos sábados (MENDONÇA et al., 2013; RIBEIRO, 2007). Portanto, objetivou- se neste trabalho, conhecer as condições físicas e sanitárias do comércio de queijo cabacinha em três municípios do Vale do Jequitinhonha, MG, Brasil.

\section{MATERIAL E MÉTODOS}

Foi realizada a prospecção do número de locais de venda de queijo cabacinha nas margens das rodovias BR 251 e BR 116, na região do Médio Jequitinhonha-MG, no mês de janeiro de 2016. Após a identificação dos locais de venda, foram escolhidos todos os comércios dos municípios de Medina $(\mathrm{n}=17)$, Cachoeira de Pajeú $(\mathrm{n}=10)$ e Pedra Azul (n $=4$ ), totalizando 31 locais

Elaborou-se uma planilha para verificação in loco das condições físicas e sanitárias dos locais de comércio. Utilizou-se como referência a Resolução da Diretoria Colegiada $n^{\circ} 275$, de 21 de outubro de 2002, da Agência Nacional de Vigilância Sanitária (ANVISA, 2002), sendo modificada para as características relacionadas às boas práticas de manuseio em pontos de venda. Nessa constavam informações quanto ao tipo de comércio, se feito em barraca, padaria ou restaurante em posto de combustíveis.

As características avaliadas foram: construção em alvenaria ou madeira; cobertura de policloreto de vinila (PVC), laje em alvenaria, telha colonial ou de amianto e paredes, se ausentes ou edificadas em alvenaria e azulejadas, revestidas com reboco e pintadas, ou somente constituídas de proteção plástica. Além dessas, constavam na planilha, informações sobre ausência ou presença de janelas e tipo de material, se feitas de madeira, metal e vidro; tipo de piso, se composto por cerâmica, cimento ou chão batido e ainda a existência ou não, e o tipo de local para a higiene das mãos, classificado em reservatório com água ou pia com torneira.

Para averiguar a forma de condicionamento do alimento para a venda, na planilha 
constavam as características de exposição do produto, se pendurado ao ar livre ou refrigerado e a presença de possíveis vetores no local de comércio, como presença de moscas, gatos, cães, dentre outros. A apresentação dos vendedores verificada no checklist foi: uso de adereços e jóias, touca e uniforme, além do manuseio simultâneo de dinheiro e do queijo artesanal.

Em fevereiro de 2016, foram realizadas várias visitas para efetuar a inspeção visual dos locais de venda e preenchimento da planilha checklist. Os dados obtidos foram contabilizados, transferidos para planilhas eletrônicas, Excel ${ }^{\circledR}$ versão 2007, e as frequências foram expressas em porcentagem.

\section{RESULTADOS E DISCUSSÃO}

Na pesquisa foram identificados 31 locais de venda do queijo cabacinha, nas rodovias BR 251 e BR 116, sendo 17 em Medina, 10 em Cachoeira de Pajeú e 4 em Pedra Azul. Porém, houve aumento do número de locais de comércio nas visitas posteriores, possivelmente, por ter ocorrido acréscimo na produção leiteira da região, influenciada por elevação do índice pluviométrico nos meses de janeiro e fevereiro 2016.

$\mathrm{Na}$ cidade de Medina, o local do comércio se caracterizava pelo aglomerado de barracas de madeira, próximas as casas dos comerciantes, enquanto nos outros dois municípios as barracas de venda eram dispersas (Figura 1). O transporte do queijo até os pontos de venda foi visualizado somente em uma barraca, o qual era realizado em embalagem plástica sobre motocicleta.

Quanto às características dos locais de venda do produto lácteo, em Medina, a maioria $(82,35 \%)$ das barracas era feita de madeira, sendo que $88,24 \%$ dos pontos de venda eram cobertos com telhas de amianto e não possuíam janela (Figura 1), 64,71\% estavam desprovidas de proteção lateral (Figuras 1 e 2) e 70,59\% das barracas não apresentavam local para lavar as mãos (Tabela 1).

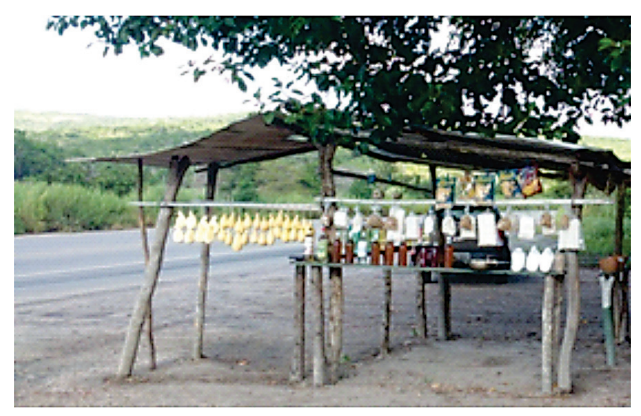

Figura 1 - Local de venda do queijo cabacinha de Medina, na margem da BR 116, coberto com telha de amianto, sem paredes e piso de terra batida. Observar os queijos pendurados em pares e presença de outros alimentos

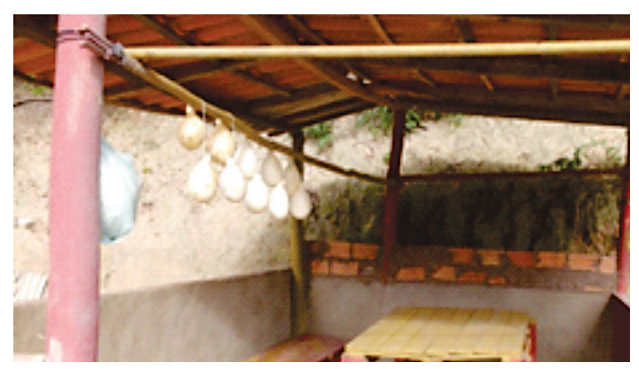

Figura 2 - Local de venda do queijo cabacinha de Pedra Azul, na BR 116, coberto com telha de cerâmica, com meia parede de alvenaria e piso de cimento. Observar à esquerda queijos condimentados com ervas e à direita queijos sem condimento e bebidas

Conforme visualizado nas Figuras 1 e 2, os queijos cabacinha eram comercializados em locais improvisados e havia oferta de queijos condimentados (Figura 2). Confirmando as observações dessa pesquisa, o maior consumo desse derivado ocorre in natura, de acordo ao citado por Laticínios Cruzília (2017) e a versão defumada foi identificada em Pedra Azul, ratificando as observações de Silveira (2015). 
Tabela 1 - Condições físicas dos locais de comercialização de queijos tipo cabacinha em três municípios do Vale do Jequitinhonha-MG

\begin{tabular}{|c|c|c|c|c|c|}
\hline & Município & $\begin{array}{l}\text { Medina } \\
(\mathrm{n}=17)\end{array}$ & $\begin{array}{c}\text { Cachoeira } \\
\text { de Pajeú } \\
(\mathrm{n}=10)\end{array}$ & $\begin{array}{l}\text { Pedra Azul } \\
\quad(n=4)\end{array}$ & $\begin{array}{c}\text { Total } \\
(\mathrm{n}=31)\end{array}$ \\
\hline Local de venda & & $\mathrm{A} / \mathrm{R}$ & $\mathrm{A} / \mathrm{R}$ & $\mathrm{A} / \mathrm{R}$ & $\mathrm{A} / \mathrm{R}$ \\
\hline \multirow{4}{*}{ Tipo } & Barraca de alvenaria & $1(5,88)$ & $2(20,00)$ & $3(75,00)$ & $6(19,35)$ \\
\hline & Barraca de madeira & $14(82,35)$ & $4(40,00)$ & $1(25,00)$ & $19(61,29)$ \\
\hline & Lanchonete ou padaria & $1(5,88)$ & $1(10,00)$ & $0(0,00)$ & $2(6,45)$ \\
\hline & $\begin{array}{l}\text { Restaurante em posto } \\
\text { de combustíveis }\end{array}$ & $1(5,88)$ & $3(30,00)$ & $0(0,00)$ & $4(12,90)$ \\
\hline \multirow{4}{*}{ Cobertura } & Forro de PVC & $1(5,88)$ & $1(10,00)$ & $0(0,00)$ & $2(6,45)$ \\
\hline & Laje & $0(0,00)$ & $4(40,00)$ & $0(0,00)$ & $4(12,90)$ \\
\hline & Telha colonial & $1(5,88)$ & $3(30,00)$ & $2(50,00)$ & $6(19,35)$ \\
\hline & Telha de amianto & $15(88,24)$ & $2(20,00)$ & $2(50,00)$ & $19(61,29)$ \\
\hline \multirow{5}{*}{ Parede } & Ausente & $11(64,71)$ & $1(10,00)$ & $1(25,00)$ & $13(41,94)$ \\
\hline & Azulejada & $1(5,88)$ & $3(30,00)$ & $0(0,00)$ & $4(12,90)$ \\
\hline & Madeira & $4(23,53)$ & $1(10,00)$ & $0(0,00)$ & $5(16,13)$ \\
\hline & Plástico & $0(0,00)$ & $1(10,00)$ & $0(0,00)$ & $1(3,23)$ \\
\hline & Reboco e tinta & $1(5,88)$ & $4(40,00)$ & $3(75,00)$ & $8(25,81)$ \\
\hline \multirow{4}{*}{ Janela } & Ausente & $15(88,24)$ & $4(40,00)$ & $2(50,00)$ & $21(67,74)$ \\
\hline & Madeira & $1(5,88)$ & $2(20,00)$ & $0(0,00)$ & $3(9,68)$ \\
\hline & Metal & $0(0,00)$ & $1(10,00)$ & $0(0,00)$ & $1(3,23)$ \\
\hline & Vidro & $1(5,88)$ & $3(30,00)$ & $2(50,00)$ & $6(19,35)$ \\
\hline \multirow{3}{*}{ Piso } & Cerâmica & $2(11,76)$ & $5(50,00)$ & $0(0,00)$ & $7(22,58)$ \\
\hline & Chão batido & $4(23,53)$ & $1(10,00)$ & $0(0,00)$ & $5(16,13)$ \\
\hline & Cimento & $11(64,71)$ & $4(40,00)$ & $4(100,00)$ & $19(61,29)$ \\
\hline \multirow{3}{*}{$\begin{array}{l}\text { Local de } \\
\text { higiene } \\
\text { das mãos }\end{array}$} & Ausente & $12(70,59)$ & $3(30,00)$ & $1(25,00)$ & $16(51,61)$ \\
\hline & Caixa de água & $3(17,65)$ & $0(0,00)$ & $0(0,00)$ & $3(9,68)$ \\
\hline & Pia & $2(11,76)$ & $7(70,00)$ & $3(75,00)$ & $12(38,71)$ \\
\hline
\end{tabular}

Nota: *A = valores absolutos e $\mathrm{R}=$ valores relativos $(\%), \mathrm{PVC}=$ Policloreto de vinila.

No município de Cachoeira de Pajeú $40 \%$ dos locais de venda eram barracas de madeira, mesmo percentual para os locais providos de cobertura com laje, os com paredes rebocadas e com janelas. $\mathrm{O}$ piso predominante nos locais de venda foi a cerâmica $(50 \%)$ e em $70 \%$ dos locais visitados existiam pia para a limpeza das mãos (Tabela 1).

Na região de Pedra Azul, predominavam as barracas de alvenaria (75\%), mesmo valor verificado para locais de venda com paredes rebocadas e providos de pia. Em 50\% dos locais de comércio visitados, a cobertura era 
com telha de cerâmica do tipo colonial ou de amianto e com ou sem janelas de vidro. Observou-se ainda que todos os pontos de venda visitados nessa região possuíam piso de cimento (Tabela 1).

Verificou-se nesta pesquisa que a exposição dos queijos cabacinha ocorria nos três municípios, na maioria dos locais de venda, conforme mostra a Tabela 2, com os queijos pendurados aos pares e em varal improvisado. Este fato pode ser explicado pela tradição de venda do produto lácteo artesanal desta maneira, conforme EMATER (2008), a qual vem dos antepassados e que deve ser preservada. Na medida do possível, novas tecnologias precisam ser propostas e implantadas para melhorar as condições de comercialização, sem descaracterizar as propriedades do produto.

Na localidade de Pedra Azul, em 100\% dos pontos de varejo, o derivado lácteo era apresentado ao consumidor pendurado aos pares. Em 50\% dos locais de comércio, além de estarem pendurados, os queijos permaneciam dentro de expositor de madeira e inox revestido por tela e com laterais cobertas por plástico. Em todos os estabelecimentos o produto lácteo era comercializado sem em- balagem e em $75 \%$ foram vistos possíveis vetores de contaminação do queijo (Tabela 2).

Nos três municípios pesquisados, $90,32 \%$ dos comerciantes penduravam os queijos aos pares e não os embalavam. Em $80,65 \%$ dos pontos de venda havia moscas, cachorros, gatos, galinhas e pássaros capazes de comprometer a qualidade sanitária do produto (Tabela 2).

Quanto ao comportamento do vendedor em pontos de venda, em Medina, 58,82\% não portavam joias ou adereços e $88,24 \%$ não utilizavam touca. A ausência de uniforme e manipulação concomitante de dinheiro e alimento aconteceu em 94,12\% dos estabelecimentos, conforme mostra a Tabela 3 .

As ações corretivas para vários dos problemas encontrados na presente pesquisa podem ser feitas por meio de conscientização e capacitação dos produtores/comerciantes em ações extensionistas da EMATER, universidades e institutos de pesquisa. Essas atividades foram realizadas com sucesso para outros produtores de queijos tradicionais de Minas Gerais, como os da região do Serro, que atualmente atingem contagens microbiológicas seguras para consumo após 17 dias de maturação (MARTINS et al., 2015).

Tabela 2 - Embalagem, presença de possíveis vetores de contaminação nos locais de venda do queijo artesanal do tipo cabacinha em três municípios do Vale do Jequitinhonha-MG, Brasil

\begin{tabular}{cccccc}
\hline & Município & $\begin{array}{c}\text { Medina } \\
(\mathrm{n}=17)\end{array}$ & $\begin{array}{c}\text { Cachoeira } \\
\text { de Pajeú } \\
(\mathrm{n}=10)\end{array}$ & $\begin{array}{c}\text { Pedra Azul } \\
(\mathrm{n}=4)\end{array}$ & $\begin{array}{c}\text { Total } \\
(\mathrm{n}=31)\end{array}$ \\
\hline Disposição & & $\mathrm{A} / \mathrm{R}$ & $\mathrm{A} / \mathrm{R}$ & $\mathrm{A} / \mathrm{R}$ & $\mathrm{A} / \mathrm{R}$ \\
\hline \multirow{2}{*}{ Armazenamento } & Pendurados & $16(94,12)$ & $8(80,00)$ & $4(100,00)$ & $28(90,32)$ \\
& Refrigerados & $1(5,88)$ & $2(20,00)$ & $0(0,00)$ & $3(9,68)$ \\
\hline \multirow{2}{*}{ Embalagem } & Ausente & $16(94,12)$ & $8(80,00)$ & $4(100,00)$ & $28(90,32)$ \\
& Saco plástico & $1(5,88)$ & $2(20,00)$ & $0(0,00)$ & $3(9,68)$ \\
\hline Vetores de & Ausente & $0(0,00)$ & $5(50,00)$ & $1(25,00)$ & $6(19,35)$ \\
contaminação & Presente & $17(100,00)$ & $5(50,00)$ & $3(75,00)$ & $25(80,65)$ \\
\hline
\end{tabular}

Nota: $* \mathrm{~A}=$ valores absolutos e $\mathrm{R}=$ valores relativos $(\%)$. 
Além disso, é essencial algum tipo de incentivo governamental para a melhor estruturação dos pontos de venda e para fornecer apoio aos treinamentos. Por ser o Vale do Jequitinhonha, região carente de recursos financeiros, conforme Ribeiro (2007) e Mendonça et al. (2013), é imprescindível criar políticas públicas direcionadas ao pequenos produtores locais de queijos que geram postos de trabalho e renda no campo.

A ausência de paredes ou barreiras físicas adequadas nos locais de venda em Medina, Cachoeira de Pajeú e Pedra Azul, conforme a Tabela 1, pode facilitar a entrada de corpos estranhos como pequenas sementes, fragmento de folhas, estercos, insetos, fuligem dos veículos que trafegam nas rodovias, dentre outros. Almeida et al. (2011) encontraram condições sanitárias similares, em feira livre às margens da BR 423, porém o comércio era de carnes, que estavam expostas a poeira e a lama. Segundo Fernandes et al. (2011) isso pode ocasionar pontos escuros e marrons em queijos, conforme foi visualizado em alguns queijos nos três locais visitados no Médio Jequitinhonha.
Os achados de Almeida et al. (2011) e Meneses et al. (2012), corroboram com os resultados desta pesquisa, ou seja, há falta de higiene dos manipuladores ou vendedores de produtos lácteos. Esse mesmo problema foi evidenciado por Almeida et al. (2011) em Paranatama (PE), que constataram que somente $4 \%$ das pessoas utilizavam touca de proteção e $83 \%$ comiam enquanto trabalhavam.

A manipulação de dinheiro e alimento simultaneamente foi evidenciada nos três municípios pesquisados e representa problema, porque o queijo é tradicionalmente vendido sem embalagem, de acordo com a Tabela 2 . Essa prática anti-higiênica não é preconizada por órgãos de saúde/vigilância e precisa ser resolvida, por meio da conscientização e treinamento dos manipuladores de alimentos, pois se trata de problema de saúde pública. Além disso, a presença de possíveis vetores de contaminação, em mais de $80 \%$ dos locais de venda de queijo cabacinha é outro fator preocupante para facilitar a contaminação microbiológica.

A ausência de embalagem em mais de

Tabela 3 - Características do vendedor de diferentes locais de venda do queijo tipo cabacinha em três municípios do Vale do Jequitinhonha, MG

\begin{tabular}{cccccc}
\hline Município & $\begin{array}{c}\text { Medina } \\
(\mathrm{n}=17)\end{array}$ & $\begin{array}{c}\text { Cachoeira } \\
\text { de Pajeú } \\
(\mathrm{n}=10)\end{array}$ & $\begin{array}{c}\text { Pedra Azul } \\
(\mathrm{n}=4)\end{array}$ & $\begin{array}{c}\text { Total } \\
(\mathrm{n}=31)\end{array}$ \\
\hline Vendedor & & $\mathrm{A} / \mathrm{R}$ & $\mathrm{A} / \mathrm{R}$ & $\mathrm{A} / \mathrm{R}$ & $\mathrm{A} / \mathrm{R}$ \\
\hline \multirow{2}{*}{ Adereços e joias } & Ausente & $10(58,82)$ & $4(40,00)$ & $2(50,00)$ & $16(51,61)$ \\
& Presente & $7(41,18)$ & $6(60,00)$ & $2(50,00)$ & $15(48,39)$ \\
\hline \multirow{2}{*}{ Uso de touca } & Sim & $2(11,76)$ & $5(50,00)$ & $1(25,00)$ & $8(25,81)$ \\
& Não & $15(88,24)$ & $5(50,00)$ & $3(75,00)$ & $23(74,19)$ \\
\hline \multirow{2}{*}{ Uso de uniforme } & Sim & $1(5,88)$ & $4(40,00)$ & $0(0,00)$ & $5(16,13)$ \\
\hline Manuseia dinheiro & Não & $16(94,12)$ & $6(60,00)$ & $4(100,00)$ & $26(83,87)$ \\
\hline e alimento & Nim & $16(94,12)$ & $6(60,00)$ & $4(100,00)$ & $26(83,87)$ \\
\hline
\end{tabular}

Nota: $* \mathrm{~A}=$ valores absolutos e $\mathrm{R}=$ valores relativos 
90\% dos locais de venda dos queijos cabacinha (Tabela 2) é também outro fator preocupante e que precisa ser resolvido, pois segundo Piscopo et al. (2015) a ausência de invólucro pode facilitar o desenvolvimento microbiológico indesejado. Porém, esta prática precisa ser mais pesquisada, pois pode alterar as características do produto tradicional.

Para o reconhecimento geográfico da região como produtora de queijo artesanal por instituições governamentais é preciso incentivo ao emprego de boas práticas de manipulação para evitar o surgimento de doenças de origem alimentar (CARLONI et al., 2016). Essa atuação pode melhorar os problemas relacionados à precariedade da maioria das instalações e promover o esclarecimento dos comerciantes. Consequentemente, o alimento tenderá a não ser considerado clandestino, além de a agroindústria familiar minimizar o êxodo rural (FERNANDES et al., 2011; HEIDTMANN JÚNIOR et al., 2014), situação comum no Vale do Jequitinhonha (RIBEIRO, 2007; MENDONÇA et al., 2013).

As ações governamentais provavelmente agregarão valor ao queijo cabacinha, se comparado aos elaborados em localidades não certificadas, como aconteceu para queijos tradicionais no Brasil (MARTINS et al., 2015) e em outros países (HUDÁKOVÁ, 2013).

\section{CONCLUSÕES}

Essa é a primeira pesquisa a levantar as condições físicas e sanitárias de locais de comercialização do queijo artesanal tipo cabacinha, na região do Médio Jequitinhonha, Minas Gerais. A produção desse tipo de queijo representa um meio de subsistência de muitas famílias da região dos municípios de Medina, Cachoeira de Pajeú e Pedra Azul.

Fica evidente que existem problemas nas estruturas dos locais de venda do produto lácteo artesanal e condições sanitárias inadequadas dos vendedores. Essas podem ser superadas com a conscientização das pessoas envolvidas, contribuição dos órgãos de vigilância sanitária municipal e estadual, além do incentivo governamental para a fixação do homem do campo.

Conclui-se que o queijo artesanal cabacinha da região do Jequitinhonha é tradicional, em consequência da ampla aceitação por consumidores locais e que visitam o médio Jequitinhonha. É necessário melhorar, com urgência, as condições de estrutura dos locais de comércio, a forma de apresentação do produto e dos vendedores, para garantir menores riscos aos consumidores. Recomenda-se que futuras pesquisas sejam realizadas para atestar a qualidade microbiológica do queijo cabacinha produzido no Vale do Jetiquinhonha, MG.

\section{REFERÊNCIAS}

AGÊNCIA NACIONAL DE VIGILÂNCIA SANITÁRIA (ANVISA). Resolução de Diretoria Colegiada, RDC $n^{\circ} 275$, de 22 de setembro de 2005. Aprova o Regulamento Técnico sobre os procedimentos operacionais padronizados e a lista de verificação das boas práticas de fabricação em estabelecimentos produtores/Industrializadores de alimentos. Diário Oficial da República Federativa do Brasil, 30 ago. 2002.

ALMEIDA, R. B. et al. Condições higiênico-sanitárias da comercialização de carnes em feiras livres de Paranatama, PE. Revista Alimentos e Nutrição, v. 22, n. 4, p. 585592, 2011.

CARLONI, E. et al. Effect of farm characteristics and practices on hygienic quality of ovine raw milk used for artisan cheese production in central Italy. Animal Science Journal, v. 87, p. 591-599, 2016.

EMATER-MG. Incentiva qualidade junto aos produtores de queijo cabacinha, 2008. 
Disponível em: <http://www.emater.mg.gov. br/portal.cgi?flagweb=site_tpl_paginas internas2\&id=1474\#. WOKDqdIrKM9>. Acesso em: 03 abr. 2017.

FERNANDES, R. V. B. et al. Avaliação físico-química, microbiológica e microscópica do queijo artesanal comercializado em Rio Paranaíba-MG. Revista do Instituto de Laticínios Cândido Tostes, v. 66, n. 382, p. 21-26, 2011.

GENTA, T. M. S. et al. Avaliação das boas práticas através de Check-list aplicado em restaurantes de self-service da região central de Maringá, Estado do Paraná. Acta Scientiarum, v. 27, n. 2, p. 151-156, 2005.

HEIDTMANN JUNIOR, D. E. D et al. A paisagem cultural e as novas possibilidades para a atividade familiar rural. Ciência Rural, v. 44, n. 11, p. 1988-1994, 2014.

HUDÁKOVÁ, J. Evaluation of the efficiency of cheese trade in Slovakia. International Journal of Trends in Economics Management \& Technology, v. 2, n. 3, p. 20-22, 2013.

\section{LATICÍNIOS CRUZÍLIA. O melhor queijo} do Brasil, 2017. Disponível em: <http://portal. sinal.org.br/wp-content/uploads/2016/02/ Catalogo.pdf>. Acesso em: 03 abr. 2017.

MARTINS, J. M. et al . Determining the minimum ripening time of artisanal Minas cheese, a traditional Brazilian cheese. Brazilian Journal of Microbiology, v. 46, n. 1, p. 219-230, 2015.

MENDONÇA, K. F. C. et al. Formação, sucessão e migração: trajetórias de duas gerações de agricultores do Alto Jequitinhonha,
Minas Gerais. Revista Brasileira de Estudos de População, v. 30, n. 2, p. 445-463, 2013.

MENESES, R. B. et al. O comércio de queijo de coalho na orla de Salvador, Bahia: trabalho infantil e segurança de alimentos. Revista de Nutrição, v. 25, n. 3, p. 381-392, 2012.

MINAS GERAIS. Instituto Mineiro Agropecuário. Portaria $n^{0} 1403$, de 02 de maio 2014. Identifica a região do Vale do Jequitinhonha como produtora de queijo cabacinha. Diário Oficial do Estado de Minas Gerais, Belo Horizonte, MG, 10 maio 2014. Disponível em: <http://jornal.iof.mg.gov.br/ xmlui/handle/123456789/121375>. Acesso em 30 ago. 2015.

MINAS GERAIS. Lei n ${ }^{\circ} 20549$, de 18 de dezembro de 2012. Dispõe sobre a produção e a comercialização dos queijos artesanais de Minas Gerais. Minas Gerais Diário do Executivo, p. 1, col. 2, 2012. Disponível em: <http://www.legisweb.com.br/ legislacao/?id=248559>. Acesso em: 18 ago. 2015.

PISCOPO, A. et al. Qualitative variations on Calabrian Provola cheeses stored under different packaging conditions. Journal of Dairy Research, v. 82, p. 499-505, 2015.

RIBEIRO, E. M. Feiras do Jequitinhonha: mercados, cultura e trabalhos de famílias rurais no semi-árido de Minas Gerais. $1^{\mathrm{a}} \mathrm{ed}$. Fortaleza: Banco do Nordeste, 2007. 246 p.

SILVEIRA, L. N. Roça, uma marca registrada: o processo de valorização do rural na sociedade brasileira. 2015. 301 f. Tese (doutorado em Extensão Rural) - Departamento de Economia Rural, Universidade Federal de Viçosa, Viçosa, 2015. 